\title{
The Development of a Single Frequency Place in the Mammalian Cochlea: The Cochlear Resonance in the Mustached Bat Pteronotus parnellii
}

\author{
Ian J. Russell, ${ }^{1}$ Markus Drexl, ${ }^{2}$ Elisabeth Foeller, ${ }^{3}$ Marianne Vater, ${ }^{4}$ and Manfred Kössl ${ }^{2}$ \\ ${ }^{1}$ School of Life Sciences, University of Sussex, Brighton BN1 9QG, United Kingdom, ${ }^{2}$ Zoological Institute, University of Frankfurt, 60323 Frankfurt, \\ Germany, ${ }^{3}$ Neurobiology Section, Division of Biology, University of California, San Diego, La Jolla, California 92093-0357, and ${ }^{4}$ Institute of Biochemistry \\ and Biology, University of Potsdam, 14471 Potsdam, Germany
}

Cochlear microphonic potentials (CMs) were recorded from the sharply tuned, strongly resonant auditory foveae of 1- to 5-week-old mustached bats that were anesthetized with Rompun and Ketavet. The fovea processes Doppler-shifted echo responses of the constantfrequency component of echolocation calls. During development, the frequency and tuning sharpness of the cochlear resonance increases, and CM ringing persists for longer after the tone. $\mathrm{CM}$ is relatively insensitive at tone onset and grows linearly with increased stimulus level. During the tone, the CM is more sensitive and grows compressively with increased stimulus level and phase leads onset $\mathrm{CM}$ by $90^{\circ}$ for frequencies below the resonance. $\mathrm{CM}$ during the ringing is also sensitive and compressive and phase leads onset $\mathrm{CM}$ by $180^{\circ}$ below the resonance and lags it by $180^{\circ}$ above the resonance. Throughout postnatal development, CMs measured during the tone and in the ringing increase both in sensitivity and compression. The cochlear resonance appears to be attributable to interaction between two oscillators. The more broadly tuned oscillator dominates the onset response, and the narrowly tuned oscillator dominates the ringing. Early in development, mechanical coupling between the oscillators results in a relatively broadly tuned system with several frequency modes in the CM at tone onset and in the CM ringing. Beating occurs between the resonance and the stimulus response during the tone and between two components of the narrowly tuned oscillator at tone offset. At maturity, the CM has three modes for frequencies within $10 \mathrm{kHz}$ of the resonance at tone onset and a single, sharply tuned mode in the ringing.

Key words: mustached bat; cochlea; microphonic potential; frequency tuning; resonance; synchronization; basilar membrane; tectorial membrane; cochlear amplifier; auditory fovea

\section{Introduction}

The mustached bat's auditory fovea is perhaps the most sharply tuned of all biological mechanical structures. This region occupies $40 \%$ of the cochlea and is used to detect the Doppler-shifted echo response of the dominant harmonic constant-frequency component (CF2) of the echolocation call at $\sim 61 \mathrm{kHz}$. In new world bats, the acquisition of an acoustic fovea is unique to mustached bats, and there is evidence that this event happened within the last 10 million years (Kössl et al., 1999). Mustached bats exploit the auditory fovea to measure target velocity and insect wing beats in the acoustic clutter of dense vegetation (Neuweiler, 1990; Schnitzler and Kalkow, 1998). The massive overexpression of the $61 \mathrm{kHz}$ region provides an opportunity to study the development of frequency tuning and amplification in a single segment of the mammalian cochlea.

\footnotetext{
Received June 2, 2003; revised Sept. 30, 2003; accepted 0ct. 6, 2003.

This work was supported by grants from the Volkswagen Foundation, the Deutsche Forschungsgemeinschaft, the Royal Society, and the Wellcome Trust. We thank Frank Coro and Emanuel Mora for providing the opportunity, stimulating environment, and discussion that facilitated these experiments and Andrei Lukashkin and Mikhail Bashtanov for stimulating discussion and helpful criticism of previous drafts of this manuscript.

Correspondence should be addressed to lan J. Russell, School of Biological Sciences, University of Sussex, Falmer, Brighton BN1 9QG, UK. E-mail i.j.russell@sussex.ac.uk.

Copyright $\odot 2003$ Society for Neuroscience $\quad$ 0270-6474/03/2310971-11\$15.00/0
}

The auditory fovea comprises a basal sparsely innervated (SI) region and a more apical densely innervated CF2 region (Fig. 1). The SI region where signals between 61 and $72 \mathrm{kHz}$ are processed is morphologically specialized with a thickened basilar membrane (BM) and club-shaped tectorial membrane (TM) (Henson and Henson, 1991), which interact together to produce a sharply tuned resonance (Suga et al., 1975; Russell et al., 2003). This resonance is detected by hair cells in the CF2 region (Kössl and Vater, 1995).

We describe the developmental changes in the auditory fovea based on measurements of the cochlear microphonic (CM). CM responses are dominated by outer hair cell (OHC) receptor potentials (Dallos et al., 1972; Russell and Sellick, 1983; Patuzzi et al., 1989). OHC cell bodies are active components of the organ of Corti (Brownell et al., 1985; Dallos, 1992), and the OHC hair bundles are inserted into the TM (Kimura, 1966; Engström and Engström, 1978). Thus, OHCs form an active mechanical link between the BM, which supports the organ of Corti, and the TM, against which the $\mathrm{OHC}$ bundles react. Measurement of the $\mathrm{CM}$ should reflect how OHCs actively respond to acoustic stimulation and contribute to tuning of the mustached bat's cochlea. Through appropriately timed electromechanical feedback, $\mathrm{OHCs}$ are believed to amplify and sharpen frequency tuning in 
the mammalian cochlea (for review, see Robles and Ruggero, 2001), and they do this by reacting with the TM (Davis, 1965; Gummer et al., 1996; Legan et al., 2000; Lukashkin and Russell, 2003). We have recorded the CM from the cochlear aqueduct of the mustached bat (Fig. 1), which provides a direct way of recording from the auditory fovea (Henson and Pollak, 1972; Henson et al., 1985). The strong resonance of the mustached bat's auditory fovea builds slowly and provides an opportunity to compare the magnitude and phase of $\mathrm{OHC}$ responses at tone onset, when cochlear amplification is weak, with those during the full manifestation of the resonance, when amplification is strong (Russell et al., 2003). Temporal analysis of the CM also provides an opportunity to examine the mechanical properties of the different cochlear components that contribute to the resonance.

Mustached bats hear in the first postnatal week. Throughout the next 5 weeks of development, the cochlear resonance shifts upward in frequency by $0.45-0.5$ octaves in parallel with the CF2 component of the echolocation call. CM becomes more sensitive, and the resonance becomes sharply tuned. Maturation of the cochlea is correlated with developmental changes in the harmonic composition and lengthening and stabilization of the CF2 component of the echolocation call (Kössl et al., 2003; Vater et al., 2003). Here, we describe the development of the underlying mechanisms that give rise to the remarkable frequency tuning of the auditory fovea.

\section{Materials and Methods}

Young mustached bats were collected in July and August in hot caves in Cuba during a period of $4-5$ weeks of postnatal development. As an estimate of age, we measured forearm length (FAL), which provides a reliable age-related index during the prevolant period of several bat species (Kunz and Anthony, 1982; Rübsamen, 1987). Newborn mustached bats have an FAL of 20-22 mm, and, at an approximate growth rate of 1 $\mathrm{mm} / \mathrm{d}$, the mature forearm length of $51-52 \mathrm{~mm}$ is attained after $4-5$ weeks (Vater et al., 2003). In the caves, the bats have a very hot and humid environment (close to $38^{\circ} \mathrm{C}$ and $100 \%$ humidity), which in this respect is comparable with the conditions in their mothers' wombs. The bats are hairless for at least 4 weeks, and they start to fly around in the cave at an age that corresponds to $46-48 \mathrm{~mm}$ forearm length. As described by Silva Taboada (1979), immature bats start to hunt close to the cave entrance region, but their insect diet is at this time still complemented by mother's milk.

Nineteen young bats were brought to a laboratory in Havana and kept 1-14 d before measurement of cochlear potentials: first postnatal week, $n=2$; second postnatal week, $n=3$; third postnatal week, $n=4$; fourth postnatal week, $n=4$; and fifth postnatal week, $n=6$. During this period of captivity, the bats' environment was kept at a high temperature of $>35^{\circ} \mathrm{C}$ and at high humidity. To measure $\mathrm{CM}$ and the compound action potential of the auditory nerve (CAP), young bats were with anesthetized with Rompun (0.01-0.06 $\mathrm{ml}$ of $0.2 \%$ solution/10 gm of body weight) alone or with a Rompun and Ketavet mixture (ketamine-HCl, $100 \mathrm{mg} /$ $\mathrm{ml}, 2 \%$ Rompun, and water in the proportion 9:1:190; dose, 0.005-0.02 $\mathrm{ml} / 10 \mathrm{gm}$ of body weight). The skull of the bats was fixed by dental acrylic to a metal bar, and an insulated tungsten electrode was introduced through the cerebellum into the cochlear aqueduct (Fig. 1A) (Henson and Pollak, 1972). During the penetration, sound stimuli were presented, and the CM response was measured. Typically, after reaching the aqueduct, there was a sudden increase in CM magnitude that did not change substantially when the electrode was advanced further. Having reached this position, we usually stopped the penetration and started the data acquisition. During the recordings, the body temperature was maintained at $38^{\circ} \mathrm{C}$ with an infrared lamp. All experimental animals were killed with an overdose of the anesthetic at the end of the experiment.

Pure tone sound stimuli of 2-10 msec duration with $1 \mathrm{msec}$ cosine rise and fall envelopes were used for acoustic stimulation. Known sound pressure levels (SPLs) were expressed in decibels SPL re: $2 \times 10^{-5} \mathrm{~Pa}$.
The stimuli were generated by a Microstar 3000a/212 or a Microstar 4200a data acquisition board and subsequently attenuated by a computer-controlled attenuator (custom made by Jim Hartley, University of Sussex). Either MicroTech Gefell 1 inch MK102.1 microphone capsules or Polaroid type 6500 sonar speaker modules were used to generate sound stimuli. In the frequency range between 30 and $70 \mathrm{kHz}$, in which the resonant phenomena occurred, the frequency response of the speakers was flat within $\pm 4 \mathrm{~dB}$. Either constant sound pressure levels (SPL in decibels re: $20 \mu \mathrm{Pa}$ ) for different frequencies (harmonic distortion, $>50 \mathrm{~dB}$ below the fundamental) were guaranteed by the use of online calculation of loudspeaker calibration curves, or the SPLs were calculated offline from the calibration curves. The responses were digitized with sample periods of $4 \mu \mathrm{sec}$ and a sampling depth of 12 bits by a Microstar board. Programs written using Testpoint (Keithley) were used to control data acquisition. In some cases the application of loud sound pressure levels of $>80 \mathrm{~dB}$ SPL caused attenuation of the response magnitude with a latency of 6-7 msec, which is typical for the effects of the middle ear muscle reflex (Suga et al., 1974; Henson et al., 1995). Data showing these characteristics were rejected.

Usually, the resonance frequency of the cochlea was defined as that stimulus frequency at which CM ringing lasting $>1 \mathrm{msec}$ after stimulus offset could be measured. In some cases (see Results) in which there was no significant ringing, the resonance frequency was determined as the stimulus frequency at which transient on-off changes occurred in $\mathrm{CM}$ amplitude. These on-off amplitude changes characterize CM responses to resonance frequency tones and have been recorded in both mature and immature bats (Kössl et al., 2003).

Animal use in this study was authorized by the Centre for the Inspection and Control of the Environment, Ministry of Science, Technology, and Environment, Cuba. The experiments comply with the Principles of Animal Care, publication 86-23, revised 1985, of the National Institutes of Health, with the Declaration of Helsinki and also with German federal regulations (approved by the Regierung von Oberbayern, 211-2531-37/98.

\section{Results}

\section{Sound-evoked electrical potentials from the cochlear duct}

The electrical signal recorded from the cochlear duct in Pteronotus parnellii in response to a tone burst consists of the CM, the CAP of the auditory nerve, and a brainstem field potential (FP; Fig. $1 B$ ). The symmetry of the CM waveform and, hence, the generation of a DC component (summating potential; Fig $2 B, D$ ), is frequency- and level-dependent and depends on the developmental stage of the bat.

The waveform of the CM recorded from adult bats for frequencies at and close to the CF echo response is symmetrical and without a measurable DC component for low- to moderate-level tones (Fig. $1 \mathrm{~B}$ ), although these traces and all others reported here are slightly skewed by the $50 \mathrm{~Hz}$ high-pass filter of the recording system. A positive DC component is evident only for tone levels above $\sim 90 \mathrm{~dB}$ SPL (data not shown). Typically, the CM contains a strong resonance with a frequency close to the Doppler-shifted CF echo response frequency (Suga et al., 1975). The CM of immature bats also contains a resonant component that outlasts the stimulus tone but usually for only a few milliseconds, depending on the tone frequency and on the developmental state of the bat. The CM recorded from the cochlea of a 3-week-old bat resonates for longer at the offset of a resonance frequency tone (Fig. $2 B, E$ ) than from the cochleas of bats at earlier developmental stages. The waveform of the CM depends on both the frequency and developmental stage of the bat. For immature bats, the resonance frequency represents a transition point for the symmetry of the response. In the example shown in Figure $2 A$, the waveform is symmetrical at all levels $<85 \mathrm{~dB}$ SPL in response to frequencies below the resonance. Hence, the DC component is negligible. For tones at the resonance frequency (e.g., $58.5 \mathrm{kHz}$ ) (Fig. $2 \mathrm{~B}$ ) that exceed a critical level, which depends on the developmental stage 


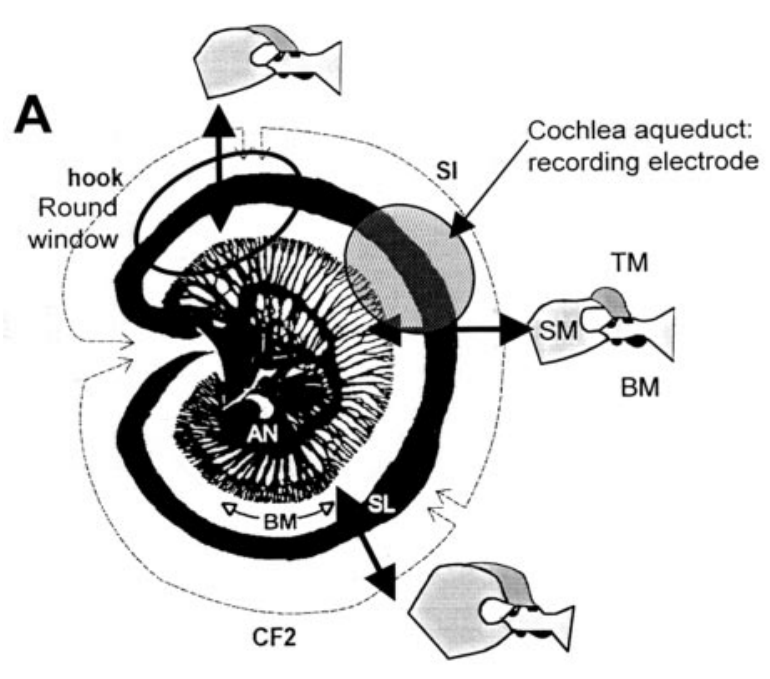

B

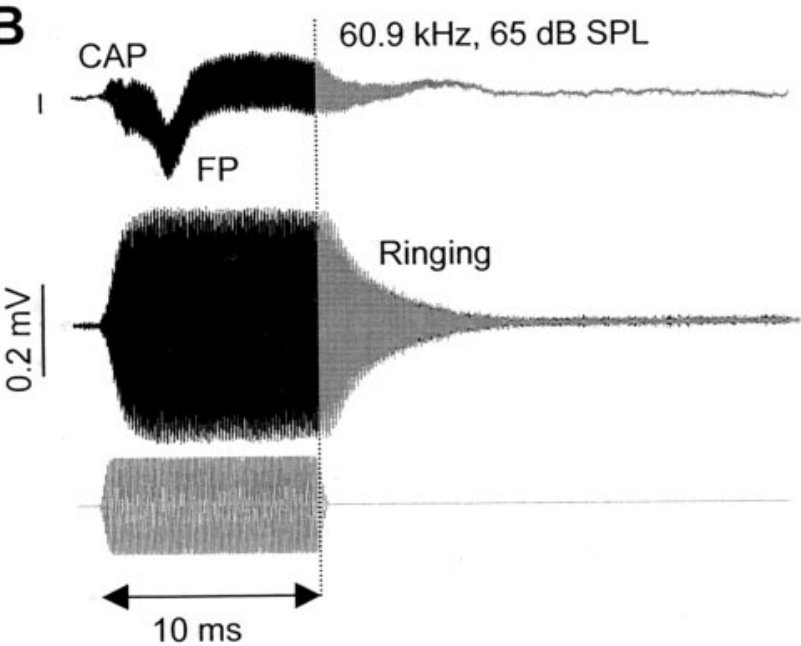

Figure 1. A, Cochlear anatomy in the mustached bat: camera lucida drawing of a whole mount of the basal turn with a round window, an auditory nerve BM, afferent nerve fibers, and spiral ligament. Two densely innervated regions (hook, CF2) are separated by an SI zone. At the transition between the SI and CF2 regions, the spiral ligament (SL) is enlarged. Cross-sections of the organ of Corti are shown where it can be seen the attachment of the TM to the spiral limbus $(S M)$ is greatly reduced, and the BM is thickened in the SI region. B, Electrical responses recorded from the cochlear ducts of a greater mustached bat with a cochlear resonance of $60.9 \mathrm{kHz}$ in response to 10 msec tones (bottom record). Top two records, $\mathrm{CM}$ to a resonance frequency tone. Note ringing indicated by gray shading. The top trace is high-pass-filtered at $50 \mathrm{~Hz}$, and the bottom trace has been bandpass-filtered from 40 to $80 \mathrm{kHz}$. Calibration, $0.2 \mathrm{mV}$. Each trace is the average of 40 recordings (modified from Russell et al., 2003).

of the bat, the CM waveform becomes asymmetrical, and a positive DC component is generated. This is $65 \mathrm{~dB}$ SPL for the CM recording shown in Figure $2 \mathrm{~B}$. For frequencies of $>1 \mathrm{kHz}$ above the resonance, the $\mathrm{CM}$ is asymmetrical at all levels above the detection threshold. Therefore, for frequencies above the resonance frequency, the CM always has a DC component (Fig. 2C) that is generated immediately at the onset of the CM response (Fig. 2D). In this case, the DC is produced by an instantaneous nonlinearity having nothing to do directly with the mechanics of the cochlea. The DC component of the CM recorded from the bat cochlea resembles that measured in guinea pig $\mathrm{OHC}$ receptor potentials in response to high-level tones, at which the DC component has been attributed to the asymmetrical transfer function of the mechanoelectric transducer channels in the OHC stereocilia (Russell et al., 1986; Russell and Kössl, 1992). In common

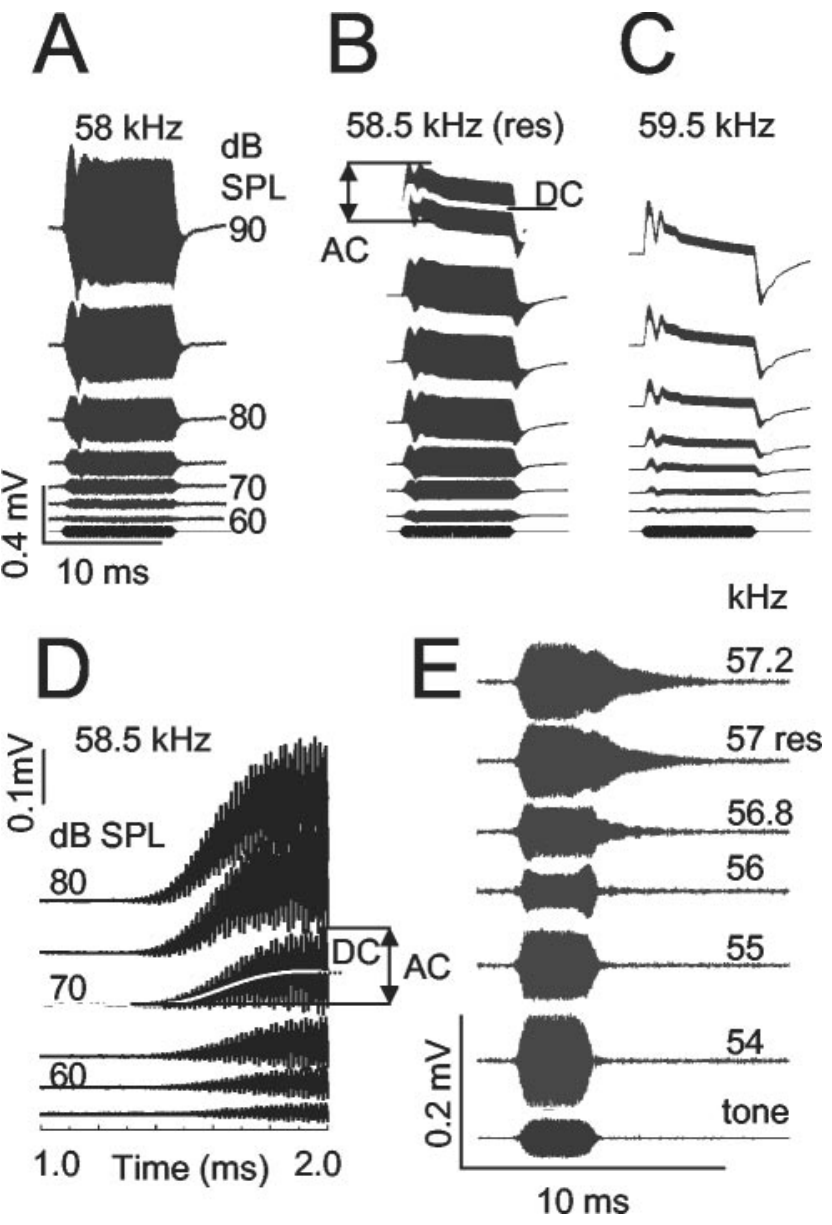

Figure 2. A-C, Electrical responses recorded from an immature bat (cmbat21; FAL, $46 \mathrm{~mm})$ in response to $10 \mathrm{msec}$ tones incremented in $5 \mathrm{~dB}$ steps (see $A$ ) at frequencies below $(A)$, at $(B)$, and above $(C)$ the resonance. $D, C M$ responses recorded from the cochlear duct of cmbat 21 to resonance frequency tones. Both the time and magnitude scales have been magnified to reveal that level-dependent differences in the onset of the $D C$ component (smooth trace) are negligible. $A C(B, D), A C$ component of the $C M ; D C(B, D), D C$ component of the $C M$. $E$, $C M$ recorded from an immature bat (cmbat31; $47 \mathrm{~mm}$ ) in response to $2 \mathrm{msec}, 75 \mathrm{~dB}$ SPL tones to show the frequency dependence of the cochlear resonance (res; $57 \mathrm{kHz}$ ). Electrical recordings in $A-D$ are high-pass-filtered at $50 \mathrm{~Hz}$; those in $E$ are bandpass-filtered between 20 and $70 \mathrm{kHz}$.

with the cochlear responses of mature bats, the magnitudes of the $\mathrm{CAP}$ and FP are minimal and have longer latencies from the onset of the tone burst at the resonance frequency than at frequencies above and below the resonance (data not shown).

Time dependence of CM frequency selectivity and amplitude sensitivity

Mechanical tuning in the SI region of the cochlea is so sharp (Kössl and Russell, 1995) that the CM takes several milliseconds to build up in response to stimulus tones at and close to the resonance frequency, and then the $\mathrm{CM}$ continues to resonate when the tone has stopped (see Figs. 1, 2). This slowing down of the responses of the cochlea provides an opportunity to investigate temporal changes in the sensory processing of acoustic signals within the first millisecond of a tone, during the steady state of the tone, and $0.5 \mathrm{msec}$ after the offset of the tone, when contributions from the stimulus tone have died away, leaving only the ringing. Measurement periods are indicated by the vertical gray bars in Figure $3 \mathrm{~A}$. CM measurements during the first millisecond of the tone are made during the $1 \mathrm{msec}$ rise time of the tone envelope that was used in these experiments to suppress 

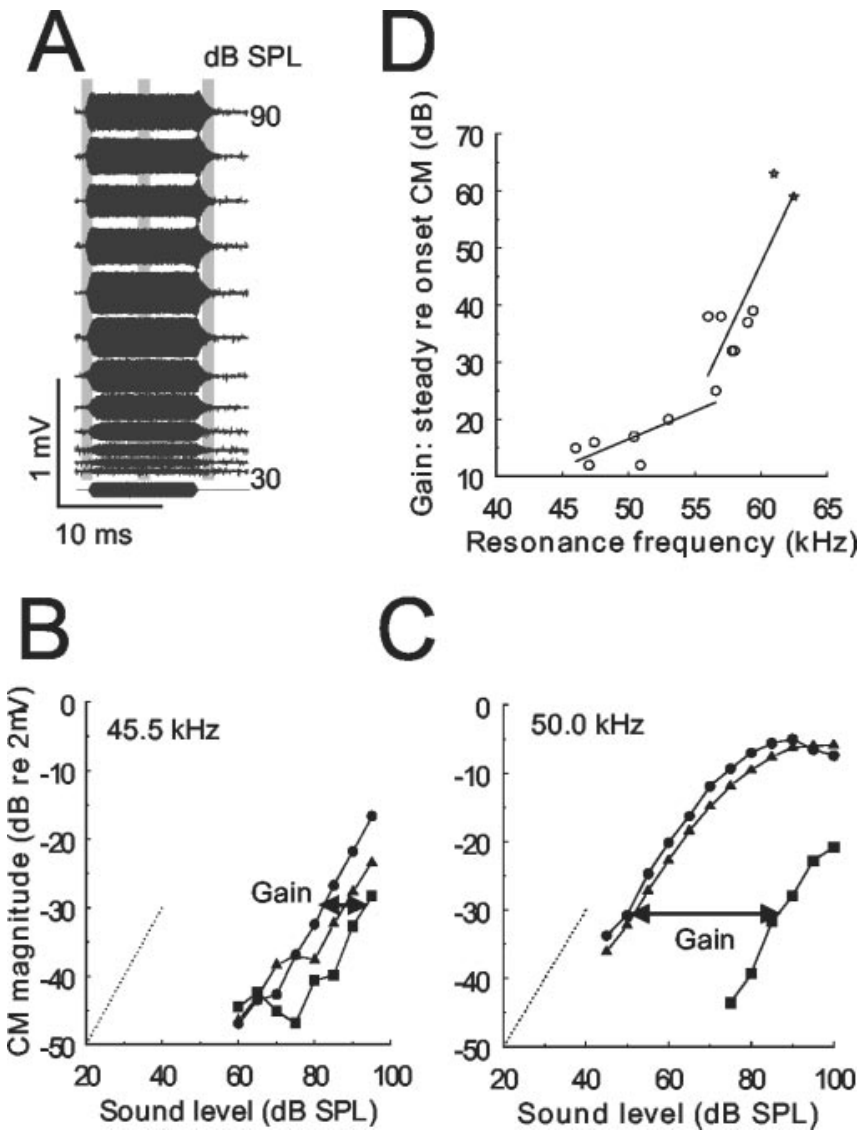

Figure 3. CM magnitude as functions of level for resonance frequency tones. $A, C M$ recorded from the cochlear aqueduct of a 5-week-old bat. CM magnitude was calculated from 8192-point FFTs applied to 1 msec time windows at the times indicated by the vertical gray bars. B, C, CM magnitude as functions of level for measurements made $0-1 \mathrm{msec}$ (squares), $4-5 \mathrm{msec}$ (circles), and 11.5-12.5 msec (triangles) from tone onset. $B$, Measurements from a 1-week-old bat (FAL, $24 \mathrm{~mm}$ ). C, Measurements from a 4- to 5 -week-old bat (FAL, $50 \mathrm{~mm}$ ). Dotted lines indicate a slope of 1 . Double arrows indicate the gain of cochlea amplification, which is the displacement along the ordinate of the ongoing relative to the onset CM level function. D, Gain of cochlea amplification as a function of the cochlear resonance frequency. Circles indicate data from 13 immature bats; stars represent data from two adult bats. Linear regressions indicate that cochlear gain increases with increased cochlear resonance frequency at different rates depending on the cochlear resonance and, hence, the developmental state (Kössl et al., 2003). For resonance of $<55 \mathrm{kHz}$, gain increases at $0.98 \pm 0.33 \mathrm{~dB} / \mathrm{kHz}$. For resonance of $>55 \mathrm{kHz}$, gain increases at $4.90 \pm 1.25 \mathrm{~dB} / \mathrm{kHz}$

stimulus onset transients. These dynamic stimulus conditions have been taken into account when calculating the magnitude of the CM during tone onset.

\section{Amplification and compression of resonance frequency CM magnitude level functions increase with time from tone onset and during development}

$\mathrm{CM}$ magnitude level functions were measured within $1 \mathrm{msec}$ of tone onset (Fig. 3A, squares), 4-9 msec from tone onset (steady state) (Fig. $3 A$, circles), and $0.5 \mathrm{msec}$ after tone offset, during the resonance (Fig. 3A, triangles) for a bat of $\sim 1$ week in age (Fig. 3B) and another $\sim 5$ weeks old (Fig. $3 C$ ). Level functions recorded from the 1-week-old bat in response to resonance frequency tones $(45.5 \mathrm{kHz}$ ) (Fig. $3 B$ ) are relatively insensitive, appearing above the noise floor at $70 \mathrm{~dB}$ SPL, and do not show compression for tone levels of $<95 \mathrm{~dB}$ SPL, which was the maximum stimulus level. Measurements made during tone onset were 10-15 dB less sensitive than those measured during the steady state. CMs mea- sured from the older bat $(59 \mathrm{kHz}$ ) (Fig. 3C) during the ongoing tone and after the offset tones close to the resonance were compressive at high SPLs and nearly $40 \mathrm{~dB}$ more sensitive than the CM magnitude level function measured at tone onset. Thus CM measured at tone onset has the characteristics of responses recorded from a passive cochlea without amplification. CM measured during the tone and after tone offset has the characteristics of responses from a cochlea with amplification. In more mature bats, the CM level functions display the compression that has been observed in the BM displacement and CM level functions of adult bats (Russell and Kössl, 1999; Russell et al., 2003). The gain of cochlear amplification, as measured by the relative displacements along the $y$-axis of the onset and steady-state level functions (Fig. 3B,C), increases with increasing age and an upward shift in resonance frequency (Kössl et al., 2003), as shown in Figure $3 D$. The relationship between the gain of cochlear amplification and the frequency of the cochlear resonance is not constant. From birth to 2 weeks of age, when the forearm length is 32-34 $\mathrm{mm}$ and the resonance is $\sim 53 \mathrm{kHz}$ (Kössl et al., 2003), the gain of cochlear amplification increases by $1 \mathrm{~dB}$ for each $1 \mathrm{kHz}$ increase in cochlear resonance. From 2 weeks of age until adulthood, the cochlear gain increases by $5 \mathrm{~dB}$ for each $1 \mathrm{kHz}$ increase in the cochlear resonance.

The resonance peak of the magnitude-frequency function is amplified, sharpened, and shifted upward in frequency with time from tone onset

Magnitude-frequency curves measured at constant sound pressure levels and at different times from tone onset are shown in Figure 4 for six bats at developmental stages that advance from newborn (Fig. 4A) to mature (Fig. $4 F$ ). The data are based on fast Fourier transforms (FFTs) applied to $1 \mathrm{msec}$ time windows with delays that are incremented in $0.2 \mathrm{msec}$ steps from 0.4 to $2 \mathrm{msec}$ and then in $1 \mathrm{msec}$ intervals to $9 \mathrm{msec}$ from tone onset. CM magnitude-frequency curves were measured during a $1 \mathrm{msec}$ window in the ringing that follows the tone commencing 0.5 msec from tone offset (Fig. 4, thick traces). Magnitude-frequency functions measured from the youngest bat (Fig. $4 \mathrm{~A}$ ) change only in magnitude and not in shape with increasing time from tone onset. The frequency-magnitude curves are also very noisy at sound levels that do not elicit noisy responses from the cochleae of more mature bats (compare Fig. $4 B-F$ ). Frequency-magnitude curves measured from bats at later developmental stages also increase in magnitude with time from tone onset. Within $1 \mathrm{msec}$ of tone onset, the curves resemble low-pass filter functions. In a slightly older specimen (Fig. $4 B$ ), the curves continue to resemble low-pass filter functions throughout the ongoing tone, whereas the ringing that follows the tone offset behaves as a resonance with a peak at $51 \mathrm{kHz}$ (dashed line). The low-pass characteristics of the frequency-magnitude curves of older bats (Fig. $4 C-F$ ) at tone onset evolve into narrowly tuned bandpass functions with increasing time from tone onset with resonance peaks (dashed lines) that match the resonance of the $\mathrm{CM}$ ringing (thick traces). In bats close to maturity (Fig. $4 E$ ), the CM magnitude-frequency functions have two peaks (Kössl et al., 2003) (dashed and dotted lines). The lower-frequency peak appears within $0.8 \mathrm{msec}$ of tone onset and becomes narrower with increasing measurement delay from tone onset. The higher-frequency peak, which is tuned to 61 $\mathrm{kHz}$ (dotted line), appears 1.8-2 msec from tone onset and is lower in frequency than the second peak in the ringing, which is tuned to $61.2 \mathrm{kHz}$. 

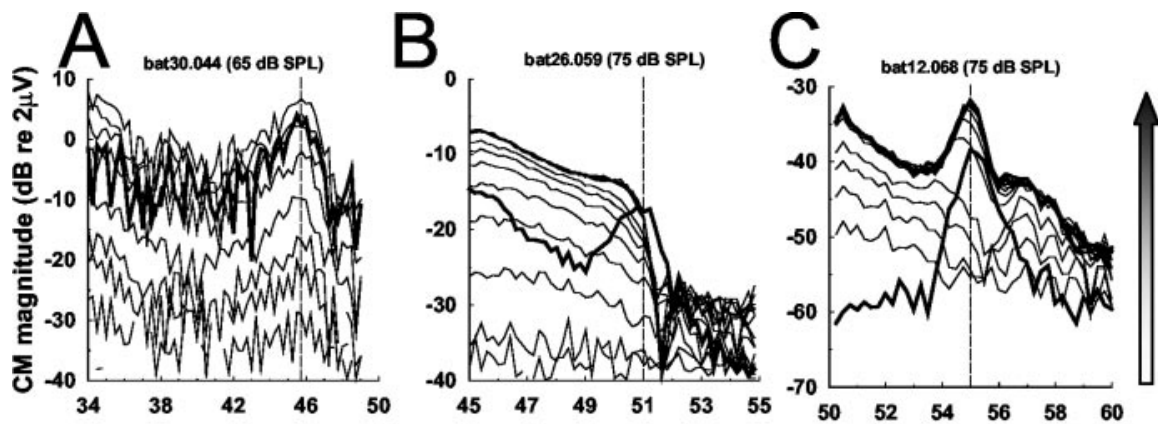

CM Phase measurements

Measurements of CM phase from the developing auditory fovea can provide information about the nature and development of cochlear amplification and the properties and development of the cochlear resonance. According to models and direct measurements from the cochlea (Geisler and Sang, 1995; Markin and Hudspeth, 1995; Gummer et al., 1996; Nilsen and Russell, 1999), cochlear amplification is optimal when energy from the OHCs is fed back at maximum basilar membrane velocity. Thus, one might expect that CM from the acoustic fovea with feedback would phase lead by $\sim 90^{\circ}$ that from the fovea without feedback. Phase measurements also provide an indication of the relative movements of the structures that form the basis of the cochlear resonance and of the frequency and sharpness of the resonance, as indicated by the appearance and slopes of the phase transitions that should accompany the resonance.

Representative examples of phase as a

Figure 4. $A-F, C M$ magnitude frequency functions for bats at increasing developmental stages. The magnitude level functions are based on 8196-point FFTs of the CM measured in a 1 msec duration sliding time window at increasing times from the onset of the 10 msec duration tones. The thin traces represent $\mathrm{CM}$ magnitude measurements taken in $0.2 \mathrm{msec}$ increments between 0.4 msec (lowest trace) and $2.0 \mathrm{msec}$ from the tone onset and then in $1 \mathrm{msec}$ increments until $10 \mathrm{msec}$ from the tone onset (highest trace). Graded arrows indicate increase in time of measurement from tone onset. The thick traces are measurements made in the CM ringing, 0.5 msec after the tone offset. $A$, cmbat30 (FAL, 21.5); B, cmbat26 (FAL, 29.5); C, cmbat12 (FAL, 38.5); D, cmbat21 (FAL, 46); $E$, 2pp13 (FAL 46); F, ppic7 (FAL, 50); bat I.D. (FAL, mm). Vertical dashed lines indicate peaks in the CM magnitude frequency functions during the tone. The vertical dotted line in $E$ indicates second peak.

function of frequency measured from the $\mathrm{CM}$ recorded from the cochleas of bats at different developmental stages, as indicated by their FALs, are shown in Figure 6 [Fig. 6A, FAL, $21.5 \mathrm{~mm}$ (week 1), $80 \mathrm{~dB}$ SPL; $B$, FAL, 29.5 mm (week 2), 60 dB SPL; $C$, FAL, $40 \mathrm{~mm}$ (week 3-4), $55 \mathrm{~dB}$ SPL; $D$, FAL, $46 \mathrm{~mm}$ (week 4-5), $60 \mathrm{~dB}$ SPL]. The corresponding magnitude functions are plotted in the bottom parts. Phase and

\section{Beating}

Beating can be recorded from the cochleas of immature bats during the ongoing tone at frequencies close to the resonance (Fig. $5 A$ ). By measuring the period of this beating, which decreases as the stimulus frequency departs from the resonance (Fig. 5A,B), it is apparent that the periodicity is attributable to beating between the stimulus and resonance. Beating disappears, and hence the beating period tends to infinity, at the resonance frequency, and this is indicated by the vertical dotted line and arrow in Figure $5 B$. The resonance can also be deduced by adding (subtracting) the difference between the stimulus frequency and the resonance frequency as the stimulus frequency passes through the resonance (Fig. 5B, squares).

The CM of some immature bats, usually those $>3$ weeks old and close to maturity, have two closely spaced peaks in the $\mathrm{CM}$ frequency response functions (CM tuning curves; Kössl et al., 2003). Beating can be observed in the CM ringing of these bats that persists for some time after the cessation of the tone burst in response to frequencies (e.g., $59.6-61.0 \mathrm{kHz}$ ) that are just above the cochlear resonance frequency $(59.4 \mathrm{kHz}$ ) (Fig. $5 A)$. The periodicity in the offset resonance is independent of the stimulus tone (Fig. $5 B$, open circles) and is attributable to the interaction between two closely spaced frequency components $(59.146$ and $60.610 \mathrm{kHz})$ that are present in the ringing (Fig. $5 C$ ). It can be seen that the frequency-magnitude curves of the ringing shown in Figure 4, although dominated by a major component, also receive contributions from other components. magnitude were measured within $1.5 \mathrm{msec}$ of tone onset (squares, $\mathrm{CM}_{\mathrm{ON}}$ ), during the steady state of the tone (4-9 msec from tone onset; filled circles, $\left.\mathrm{CM}_{\text {Steady }}\right)$, and 0.5-1.5 msec after tone offset (triangles, $\left.\mathrm{CM}_{\mathrm{OFF}}\right)$. Phase differences $\left(\mathrm{CM}_{\text {Steady }}-\right.$ $\mathrm{CM}_{\mathrm{ON}}$, thin line; $\mathrm{CM}_{\mathrm{OFF}}-\mathrm{CM}_{\mathrm{ON}}$, thick line) are shown in the top-most parts.

Phase-frequency relations of $C M_{O N}$

For frequencies within $5 \mathrm{kHz}$ below the cochlear resonance, the slope of the $\mathrm{CM}_{\mathrm{ON}}$ phase-frequency relationship is $100-120 \%$ $\mathrm{kHz}$. For frequencies within $0.2-0.4 \mathrm{kHz}$ of the resonance frequency, $\mathrm{CM}_{\mathrm{ON}}$ phase becomes almost constant and frequencyindependent. For frequencies above resonance, $\mathrm{CM}_{\mathrm{ON}}$ returns to a phase lag of $100-120^{\circ} / \mathrm{kHz}$ with increasing frequency.

\section{$C M_{\text {Steady }}$ phase leads $C M_{O N}$ below the resonance}

The thin solid lines in the top parts of Figure 6 represent the phase difference between the $\mathrm{CM}_{\mathrm{ON}}$ and $\mathrm{CM}_{\text {Steady }}$. $\mathrm{CM}_{\text {Steady }}$ leads $\mathrm{CM}_{\mathrm{ON}}$ by $\sim 90^{\circ}$ for frequencies below the resonance in all bats of different developmental stages. The slope of $\mathrm{CM}_{\text {Steady }}$ is similar to that of $\mathrm{CM}_{\mathrm{ON}}\left(100-120^{\circ} / \mathrm{kHz}\right) ; \mathrm{CM}_{\mathrm{ON}}$ continues to lag $\mathrm{CM}_{\text {Steady }}$ for frequencies above the resonance in recordings made from the two most immature bats (Fig. $6 A, B$ ). $\mathrm{CM}_{\mathrm{ON}}$ and $\mathrm{CM}_{\text {Steady }}$ are in phase for frequencies within $1 \mathrm{kHz}$ above the resonance in the more mature bats (Fig. 6C,D).

$C M_{O F F}$ phase leads and then lags $C M_{O N}$ below and above the resonance

The thick lines in the top parts of Figures 6 represent the phase difference between $\mathrm{CM}_{\mathrm{OFF}}$ and $\mathrm{CM}_{\mathrm{ON}}$. The phase of $\mathrm{CM}_{\mathrm{OFF}}$ leads 
$\mathrm{CM}_{\mathrm{ON}}$ by $\sim 180^{\circ}$ for frequencies within 1 $\mathrm{kHz}$ below the resonance and lags $\mathrm{CM}_{\mathrm{ON}}$ by a similar amount within $1 \mathrm{kHz}$ above the resonance (Fig. 6). The slope of the $\mathrm{CM}_{\mathrm{OFF}}$ phase-stimulus frequency relationship is very steep through the resonance, and it intersects the phase-stimulus frequency relationships of $\mathrm{CM}_{\mathrm{ON}}$ and $\mathrm{CM}_{\text {Steady }}$, an indication that a very sharp resonator produces $\mathrm{CM}_{\mathrm{OFF}}$.

At all developmental stages and for frequencies within $500 \mathrm{~Hz}$ of the resonance, $\mathrm{CM}_{\text {ON }}$ phase lags $\mathrm{CM}_{\text {Steady }}$ for frequencies below the resonance by $97.7 \pm 13.4^{\circ}$ (mean $\pm \mathrm{SD} ; n=11$ ). This is an indication that at tone onset in the cochlear fovea, amplification is minimal and occurs at maximum $\mathrm{BM}$ velocity during $\mathrm{CM}_{\text {Steady }}$. In all but the two bats from which we made measurements (data from one of which is shown in Fig. 6A) $\mathrm{CM}_{\text {Steady }}$ and $\mathrm{CM}_{\mathrm{ON}}$ are almost in phase for frequencies immediately above the resonance; i.e., $\mathrm{CM}_{\mathrm{ON}}$ phase lags $\mathrm{CM}_{\text {Steady }}$ by $6.6 \pm 9.3^{\circ}$ (mean $\pm \mathrm{SD} ; n=9$ ). In the two youngest bats, $\mathrm{CM}_{\mathrm{ON}}$ phase lags $\mathrm{CM}_{\text {Steady }}$ for frequencies above the resonance by $81.6^{\circ}$ (Fig. $6 A$ ) and $92.3^{\circ}$ (data not shown), respectively. In all bats, including the youngest, for which this analysis was performed, $\mathrm{CM}_{\mathrm{OFF}}$ phase leads $\mathrm{CM}_{\mathrm{ON}}$ by $\sim 180^{\circ}$ for frequencies below the resonance $\left(176.7 \pm 23.5^{\circ}\right.$, mean $\left.\pm \mathrm{SD} ; n=11\right)$ and lags $\mathrm{CM}_{\mathrm{ON}}$ by a similar amount for frequencies above the resonance $\left(180.8 \pm 17.3^{\circ}\right.$, mean $\pm \mathrm{SD} ; n=$ 11 ), thereby resulting in a sharp transition in phase of $\mathrm{CM}_{\mathrm{OFF}}$ at the resonance frequency.

\section{Temporal changes in CM frequency functions}

Temporal changes in CM responses were measured to tones at frequencies near the resonance. We measured the frequency of the $\mathrm{CM}$ at $0.1 \mathrm{msec}$ intervals during the first $2 \mathrm{msec}$ of the tone and then at intervals of $1 \mathrm{msec}$ during the remainder of the 10 msec tone and for up to $5 \mathrm{msec}$ after the cessation of the tone. These measurements were made for a series of tones stepped either in 0.1 or $0.2 \mathrm{kHz}$ increments from 2 to $5 \mathrm{kHz}$ above and below the resonance frequency. The frequency was measured from 8192-point FFTs that were applied to $1 \mathrm{msec}$ sample periods of the CM. Figure $7 A$ gives an example of $\mathrm{CM}$ frequency as a function of time recorded from a 4 -week-old immature, bat (FAL, $48 \mathrm{~mm}$ ) in response to $10 \mathrm{msec}$ tone bursts that are incremented in $0.2 \mathrm{kHz}$ steps from 53 to $63 \mathrm{kHz}$. The vertical gray bars indicate the sample periods at tone onset, at steady state, and after the cessation of the tone during which measurements were made to provide the data shown in Figure $7 B$. In Figure $7 B$ is shown the frequency (top part, thin line) and amplitude (bottom part, stars) of the CM measured at tone onset $\left(\mathrm{CM}_{\mathrm{ON}}\right)$ and the frequency (top part, thick line) and amplitude (bottom part, triangles) of the $\mathrm{CM}$ in the ringing that follows the tone $\left(\mathrm{CM}_{\mathrm{OFF}}\right)$ as functions of stimulus frequency. At tone onset, $\mathrm{CM}_{\mathrm{ON}}$ responds not to the stimulus frequency (diagonal dotted line) but is several hundred hertz less than this. The frequency of $\mathrm{CM}_{\mathrm{OFF}}$ changes with increasing stimulus frequency at an average rate of $0.83 \pm 0.2$
$\mathrm{Hz} / \mathrm{Hz}$ from 53 to $63 \mathrm{kHz}$ (Fig. 7B). The change is irregular and occurs in discrete steps (arrows). Between frequency steps, $\mathrm{CM}_{\mathrm{OFF}}$ frequency remains constant for several hundred hertz, and in the stimulus frequency range of $55.5-59.5 \mathrm{kHz}$, the frequency of $\mathrm{CM}_{\mathrm{OFF}}$ remains constant at the frequency of the principle resonance, which for this bat is $58.2 \mathrm{kHz}$.

In Figure 8, CM frequency as a function of stimulus frequency is shown for four bats at increasing stages of development (Fig. $8 A$, FAL, $21.5 \mathrm{~mm}, 80 \mathrm{~dB}$ SPL; $B, 29.5 \mathrm{~mm}, 65 \mathrm{~dB}$ SPL; $C, 48 \mathrm{~mm}$, $65 \mathrm{~dB}$ SPL; $D, 50 \mathrm{~mm}, 65 \mathrm{~dB}$ SPL). The frequency of $\mathrm{CM}_{\mathrm{ON}}$ (top parts, thin lines) recorded from the youngest bat (Fig. $8 \mathrm{~A}$ ) increases with increasing stimulus frequency in a series of discrete steps, which are indicated by arrows in Figure $8 A$. The transitions in the steps are associated with minima in the magnitude frequency functions of $\mathrm{CM}_{\mathrm{ON}}$ (stars), as indicated by arrows in the bottom traces of Figure $8 \mathrm{~A}$. The frequency of $\mathrm{CM}_{\mathrm{OFF}}$ (which, for clarity, has been displaced by $2 \mathrm{kHz}$ to higher frequencies) also increases as a series of steps. These steps are not as defined as those in $\mathrm{CM}_{\mathrm{ON}}$, and the interstep frequency is 1.5 times that of $\mathrm{CM}_{\mathrm{ON}}$. There is a small region that extends $\sim 1 \mathrm{kHz}$ above the resonance (bottom part, filled triangles), indicated by the horizontal dashed line in the top part, where the frequency of $\mathrm{CM}_{\mathrm{OFF}}$ is independent of stimulus frequency. With advancing development, the dependence of $\mathrm{CM}_{\mathrm{ON}}$ on stimulus frequency remains stepwise, although the steps may not always be so clearly apparent as that seen in the youngest bat. Thus, the frequency of $\mathrm{CM}_{\mathrm{ON}}$ hunts at approximately the stimulus frequency either with transient excursions (see Figs. 7, 8A, $B, 10 A$ ) as in the youngest bats or with smooth excursions (Fig. $8 C, D$ ). These differences are attrib- 

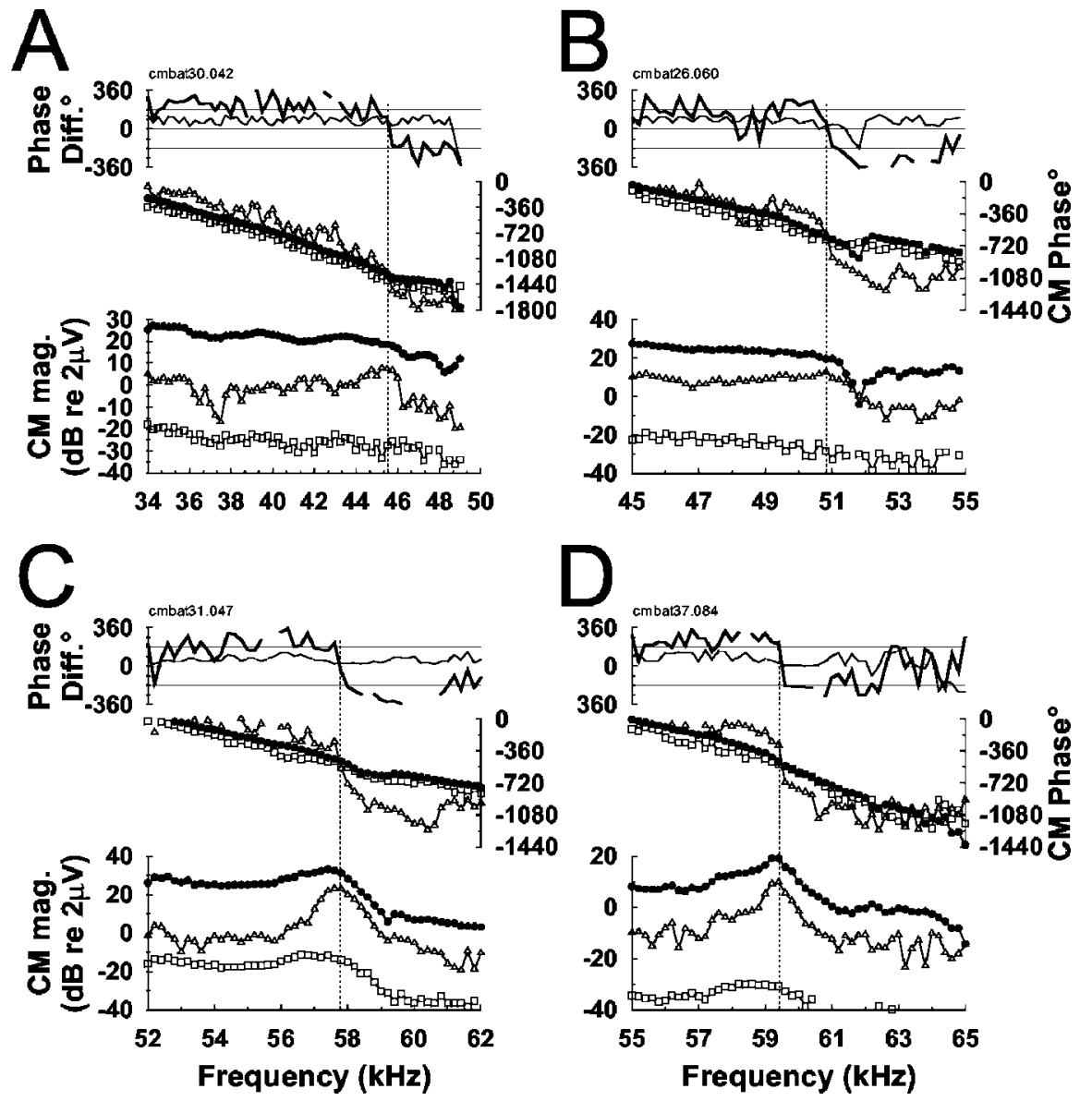

Figure 6. $A-F, C M$ phase (top part) and $C M$ magnitude (bottom part) as functions of frequency for four immature bats $(A, F A L$, $21.5 \mathrm{~mm}, 80 \mathrm{~dB}$ SPL; $B$, FAL, $29.5 \mathrm{~mm}, 60 \mathrm{~dB}$ SPL; C, FAL, $40 \mathrm{~mm}, 55 \mathrm{~dB}$ SPL; D, FAL, $46 \mathrm{~mm}, 60 \mathrm{~dB}$ SPL.) Open squares, Measurements within 1 msec of tone onset of a 10 msec tone (onset); filled circles, measurements beginning 6 msec of tone onset (steady state); open triangles, measurements beginning $0.5 \mathrm{msec}$ after the tone offset (offset). Top part, Thick line, Offset phase onset phase; thin line, steady state - onset phase; vertical dotted line, resonance frequency. All measurements were based on 8196-point FFTs applied to 1 msec sample periods of the CM responses to 10 msec tones.

utable to subtle differences between cochleae in the development of $\mathrm{CM}$ from tone onset because $\mathrm{CM}_{\mathrm{ON}}$ progresses from stepwise to smooth excursion at approximately the stimulus frequency with increasing time from tone onset (see Fig. 10C). In some bats, the mean of $\mathrm{CM}_{\mathrm{ON}}$ tends to be proportional to stimulus frequency; e.g., the regression of $\mathrm{CM}_{\mathrm{ON}}$ recorded from cmbat 21 (Fig. $7 B$ ) is $0.83 \pm 0.02 \mathrm{~Hz} / \mathrm{Hz}$, and that recorded from cmbat 26 (Fig. $8 \mathrm{~B}$ ) is $0.94 \pm 0.02 \mathrm{~Hz} / \mathrm{Hz}$. With advancing development, the frequency of $\mathrm{CM}_{\mathrm{OFF}}$ becomes more stable and constant in response to stimulus frequencies at approximately the resonance (Figs. $8 B-D, 9 A$ ). Even stimulus frequencies $>2 \mathrm{kHz}$ above the resonance cause ringing at the primary resonance frequency $(59.54 \mathrm{kHz})$ at the tone offset. A second resonance peak in the $\mathrm{CM}_{\mathrm{OFF}}$ frequency-stimulus frequency relationship shown in Figure $8 C$ in response to a stimulus frequency of $63.5 \mathrm{kHz}$ causes a ringing at the primary resonance frequency of $59.54 \mathrm{kHz}$.

In all specimens irrespective of age, $\mathrm{CM}_{\mathrm{ON}}$ is always a few hundred hertz below that of $\mathrm{CM}_{\mathrm{OFF}}$ when driven by a resonance frequency tone. This difference in frequency response is made more apparent in Figure 9A. The frequency difference between $\mathrm{CM}_{\mathrm{ON}}$ and $\mathrm{CM}_{\mathrm{OFF}}$ in response to stimulus frequency tones tends to decrease during development, as shown in Figure 9B, where $\mathrm{CM}_{\mathrm{OFF}}-\mathrm{CM}_{\mathrm{ON}}$ is plotted as a function of cochlear resonance frequency, which increases during development (Kössl et al.,
2003). The regression slope is $-0.0273 \pm$ 0.006 , and the relationship is given as $\mathrm{CM}_{\mathrm{OFF}}-\mathrm{C}_{\mathrm{MON}}=-0.0273\left(\mathrm{CM}_{\mathrm{OFF}}\right)+$ 1.834, which provides an intercept of $\sim 65$ $\mathrm{kHz}$, which is $\sim 3 \mathrm{kHz}$ above the resonance for an mature bat.

The frequency dependence of $\mathrm{CM}_{\mathrm{ON}}$ and $\mathrm{CM}_{\mathrm{OFF}}$ during development is very similar to that measured from the cochleas of adult bats (Russell et al., 2003). This similarity is exemplified by measurements made from a bat at an advanced developmental stage (FAL, $47 \mathrm{~mm}$; Fig. 10). The frequency of $\mathrm{CM}_{\mathrm{OFF}}$ increases as a series of discrete steps with increasing stimulus frequency (Fig. 10A, horizontal dashed lines), an indication that the oscillator that is responsible for the sustained ringing that follows tone offset can switch from one frequency mode to another depending on the frequency of the driving tone. $\mathrm{CM}_{\mathrm{ON}}$ behaves as if it is generated by an oscillator that is attracted to the stimulus frequency and has several frequency modes that are related to those of the $\mathrm{CM}$ OFF oscillator but with frequencies $\sim 1 \mathrm{kHz}$ below those of the $\mathrm{CM}_{\mathrm{OFF}}$ oscillator. Coupling between the $\mathrm{CM}_{\mathrm{ON}}$ oscillator and the stimulus frequency increases with the time from the measurement of the frequency of $\mathrm{CM}_{\mathrm{ON}}$ from tone onset. This is shown in Figure $10 B$, where CM frequency is plotted as a function of stimulus frequency for $\mathrm{CM}$ frequency measured with delays of 0.3-0.9 msec from tone onset. With increasing delay, the CM frequency approaches more closely the stimulus frequency (diagonal dotted line). Within the $52-62 \mathrm{kHz}$ frequency range, $\mathrm{CM}_{\mathrm{ON}}$ frequency intersects and crosses the stimulus frequency at 52.3, 56.8, and $60.8 \mathrm{kHz}$ (vertical dotted lines, natural frequency modes of onset oscillator) (Fig. $10 \mathrm{D}$ ) and at 54.55 and $58.8 \mathrm{kHz}$ (vertical dashed lines, transition frequencies of the principal modes of the onset oscillator). The transition frequencies indicate the bandwidth of the principal mode of the cochlear resonance region (Russell et al., 2003).

The relation between $\mathrm{CM}$ frequency and stimulus frequency is more apparent in Figure $10 C$, where the frequency difference between the CM and the stimulus is plotted against stimulus frequency. When measured only $0.3 \mathrm{msec}$ from tone onset, $\mathrm{CM}_{\mathrm{ON}}$ is most strongly attracted away from the stimulus at the transition frequency close to $55 \mathrm{kHz}$ and progresses from stepwise to smooth excursions at approximately the stimulus frequency with increasing time from tone onset (Fig. 10C). Thus, the differences seen in frequency dependence of $\mathrm{CM}_{\mathrm{ON}}$ among different specimens of young bats (Figs. 7, 8D, 10A) may be attributable to subtle differences between cochleas in the development of CM from tone onset. In Figure $10 D$, the phase, frequency, and magnitude of $\mathrm{CM}_{\mathrm{ON}}$ measured $0.6 \mathrm{msec}$ from tone onset are plotted as functions of stimulus frequency. The frequency transitions (vertical dashed lines) are associated with magnitude minima and phase transitions. Within the stimulus frequency range of $52-62 \mathrm{kHz}$, there are three frequency modes 
of $\mathrm{CM}_{\mathrm{ON}}$ at $52.3,56.8$, and $60.8 \mathrm{kHz}$, which are shown by the vertical dotted lines in Figure $10 \mathrm{D}$. When measured with a delay of $0.6 \mathrm{msec}$ from tone onset, the relative coupling between the frequency modes of the onset oscillator and the stimulus frequency causes the frequency of $\mathrm{CM}_{\mathrm{ON}}$ to change at a rate of $0.39 \mathrm{~Hz} / \mathrm{Hz}$ with stimulus frequency between the transition points.

\section{Discussion}

\section{Amplification and compression} increase with cochlear maturation

The echo-processing $61 \mathrm{kHz}$ region of the mustached bat's cochlea (auditory fovea) provides a unique opportunity to investigate the development of a single frequency place on the cochlea by using the relatively noninvasive technique of measuring $\mathrm{CM}$ from the cochlear aqueduct, which is dominated by $\mathrm{OHC}$ responses from the fovea.

In response to resonance frequency tones, $\mathrm{CM}_{\text {Steady }}$ recorded from the mature bat cochlea grows compressively with increasing level (Russell et al., 2003). $\mathrm{CM}_{\text {Steady }}$ is $50-60 \mathrm{~dB}$ more sensitive at low levels and is more sharply tuned than the linear growth of $\mathrm{CM}_{\mathrm{ON}}$, which $\mathrm{CM}_{\text {Steady }}$ phase leads by $90^{\circ}$. The increased sensitivity and compression of $\mathrm{CM}_{\text {Steady }}$ compared with $\mathrm{CM}_{\mathrm{ON}}$ has been taken to indicate that at tone onset, the CM is from a passive cochlea. Over a $>1$ msec, OHCs amplify the responses of the cochlea by boosting the vibration of the BM during maximum velocity, and they compress the responses of the cochlea at high levels (for review, see Robles and Ruggero, 2001; Russell et al., 2003). This process begins in the first week of a mustached bat's life, when $\mathrm{CM}_{\text {Steady }}$ is $10-15 \mathrm{~dB}$ more sensitive than $\mathrm{CM}_{\mathrm{ON}}$. By the fifth week, $\mathrm{CM}_{\text {Steady }}$ is $35-40 \mathrm{~dB}$ more sensitive than $\mathrm{CM}_{\mathrm{ON}}$. Amplification develops slowly for the first 2 weeks of life and then accelerates in the second to fifth weeks (Fig. 3D). By contrast, tuning of the resonance develops rapidly over the first 3 weeks of development and then slows down (Kössl et al., 2003). Thus, the development of cochlear amplification occurs separately and continues after the development of frequency tuning has begun to asymptote.

\section{Transducer operating point shifts during development}

From birth, $\mathrm{CM}_{\mathrm{ON}}$ phase leads $\mathrm{CM}_{\text {Steady }}$ by $90^{\circ}$ below the resonance, an indication that the timing of cochlear feedback appears to be close to optimal at maximum BM velocity. However, neither the gain nor the frequency tuning of the immature bat cochlea matches that of the mature cochlea. One possible reason for this discrepancy is that OHCs in the immature bat cochlea do not always operate at approximately the most sensitive point of the hair cell transducer function (Russell et al., 1986). The CM, recorded from mature bats, is symmetrical for frequencies above and below the resonance for levels of $<80 \mathrm{~dB}$ SPL (Russell et al., 2003). This finding agrees with basal turn OHC responses from nonecholocating mammals (Russell et al., 1986), in which OHC hair bundles react against the TM (Legan et al., 2000) so that $\sim 50 \%$ of the transducer channels are open at rest, OHCs operate at the steepest point on the transducer function, and the DC

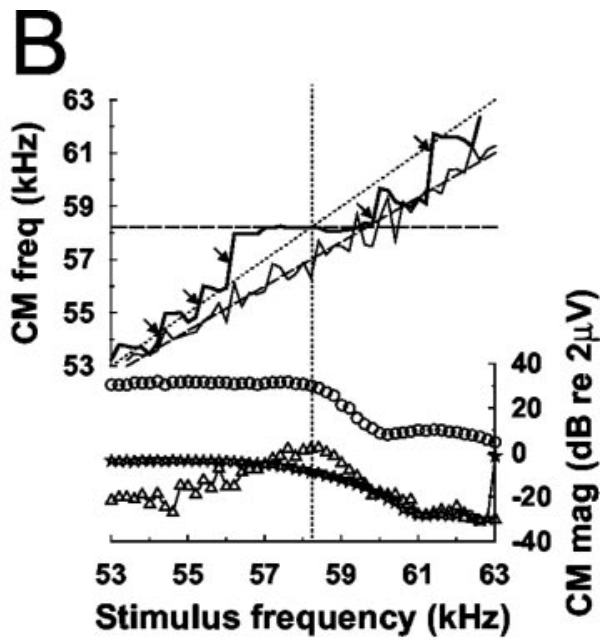

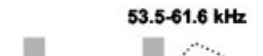
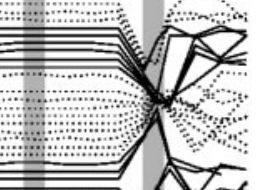

$10 \quad 15$

Time (ms)

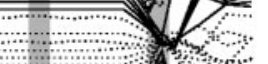

Stimulus frequency $(\mathbf{k H z})$

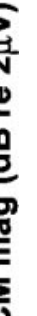

Figure 7. A, CM frequency recorded from the cochlea of an immature bat (cmbat21; FAL, $46 \mathrm{~mm}$ ) as a function of time for 10 from guiding the eye. $B$, CM frequency (top part) and CM magnitude (CM mag; bottom part) as functions of stimulus frequency. ves are derived from 8196-point FFTs applied to 1 msec sample periods (see vertical gray bars in $A$ ) measured for $0 \mathrm{msec}\left(\mathrm{CM}_{\mathrm{ON}}\right.$; component is negligible (Russell and Kössl, 1992). OHCs appear not to function at approximately their most sensitive operating point in immature bats, as indicated by a DC component that is present at all levels for frequencies at and just above the resonance; with the consequence that cochlear feedback is not optimal. It is suggested that the axial OHC motility (Brownell et al., 1985 ) is responsible for maintaining the OHC operating point (Russell and Kössl, 1992). Perhaps in the cochleas of immature bats ( $<4-5$ weeks old), at and above the resonance frequency, the mechanical impedance of the cochlear partition is too great for OHCs to exert sufficient force against the TM to minimize the receptor potential DC component and thereby to maintain the operating point of the transducer function at its most sensitive position.

\section{The oscillator frequencies move together and upward} during development

$\mathrm{CM}$ and micromechanical measurements (Kössl and Russell, 1995; Russell and Kössl, 1999; Russell et al., 2003) from the SI region of the mustached bat's cochlea have led to the proposal that the cochlear resonance is attributable to $\mathrm{OHC}$-mediated feedback between two oscillators that have been attributed to the TM and the BM.

During development, the frequency of the cochlear resonance shifts upward from $\sim 45 \mathrm{kHz}$ in postnatal week 1 to $\sim 60 \mathrm{kHz}$ in postnatal week 5 , and the frequency separation between $\mathrm{CM}_{\mathrm{ON}}$ and $\mathrm{CM}_{\mathrm{OFF}}$ decreases from 0.6 to $0.2 \mathrm{kHz}$. The large frequency gap between the two oscillators in the first week of life may partially account for the finding that $\mathrm{CM}_{\text {Steady }}$ continues to lead $\mathrm{CM}_{\mathrm{ON}}$ for frequencies above the resonance in the two youngest bats in this study. In older bats, the oscillators are closer in frequency and become mass-limited and, hence, in phase at approximately the same frequency. However, the individual characteristics of the two oscillators tend to remain constant throughout development, at least from week 2 onward, in that the offsetoscillator (TM) is more sharply tuned and takes longer to build up its responses to the resonance frequency than does the broadly 

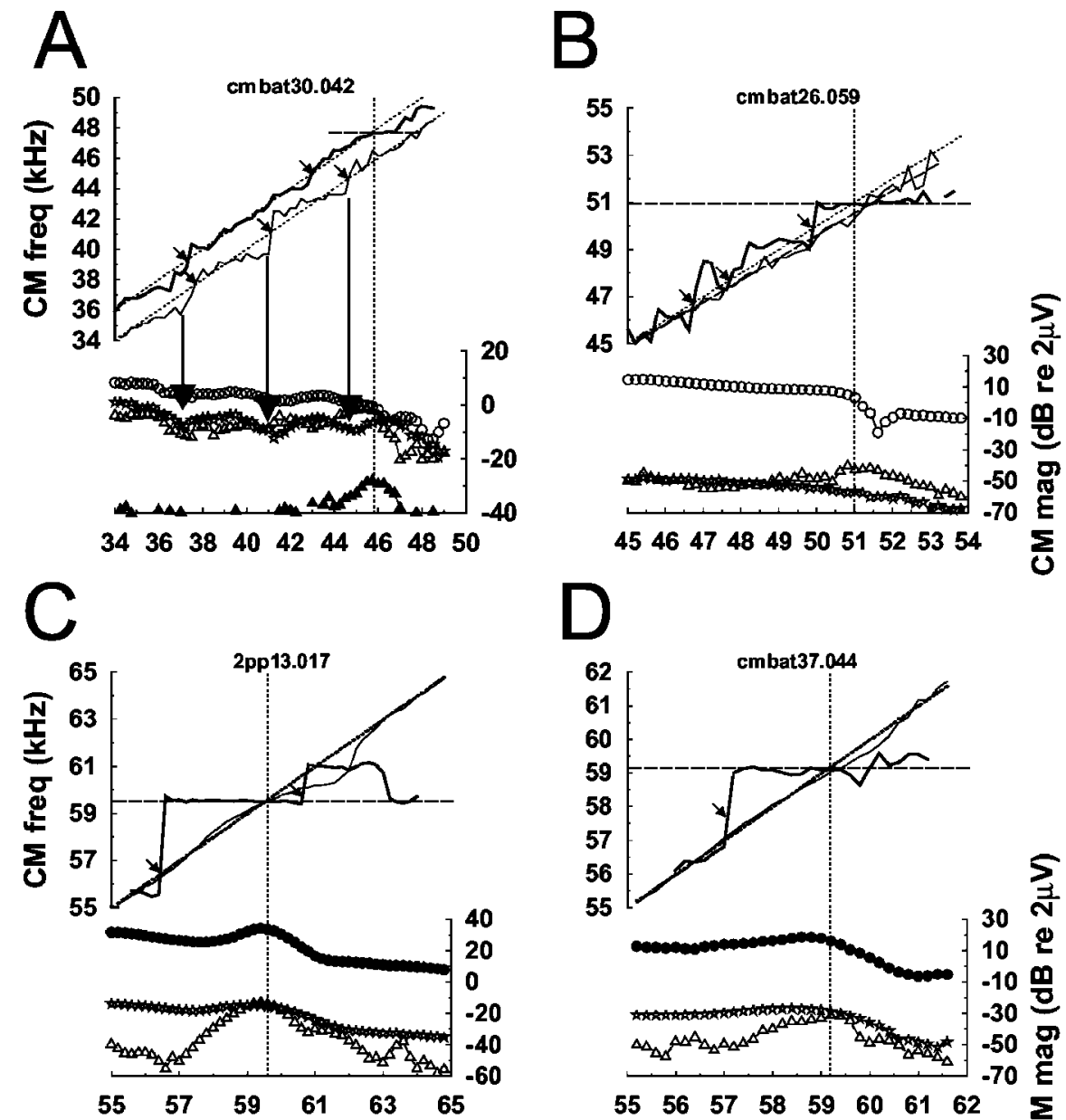

Stimulus frequency $(\mathrm{kHz})$
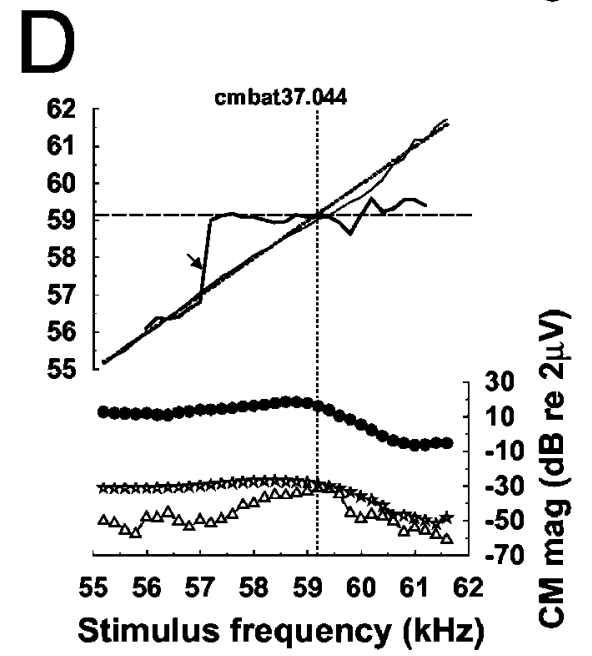

Figure 8. C CM frequency (top parts) and CM magnitude ( $C M$ mag; bottom parts) as functions of stimulus frequency measured in immature bats ( $A$, FAL, $21.5 \mathrm{~mm}, 80 \mathrm{dBSPL} ; B, 29.5 \mathrm{~mm}, 65 \mathrm{~dB} \mathrm{SPL}$; C, $48 \mathrm{~mm}, 65 \mathrm{dBSPL}$ ). Curves are derived from 8196-point FFTs applied to 1 msec sample periods (see vertical gray bars in 7A) measured 0 msec (top traces, thin line; bottom traces, stars) and 6 msec (circles) from the tone onset and 0.5 msec from the tone offset (top parts, thick lines; bottom parts, triangles). Diagonal dotted line, $\mathrm{CM}$ frequency = stimulus frequency (this line and $\mathrm{CM}$ offset frequency shifted by $2 \mathrm{kHz}$ for clarity in $A$ ); horizontal dashed line, resonance frequency; arrows, frequency modes in $\mathrm{CM}_{\mathrm{OFF}}$ and also in $\mathrm{CM}_{\mathrm{ON}}$ in $A$; vertical dotted line, peak of $\mathrm{CM}_{\mathrm{OFF}}$.
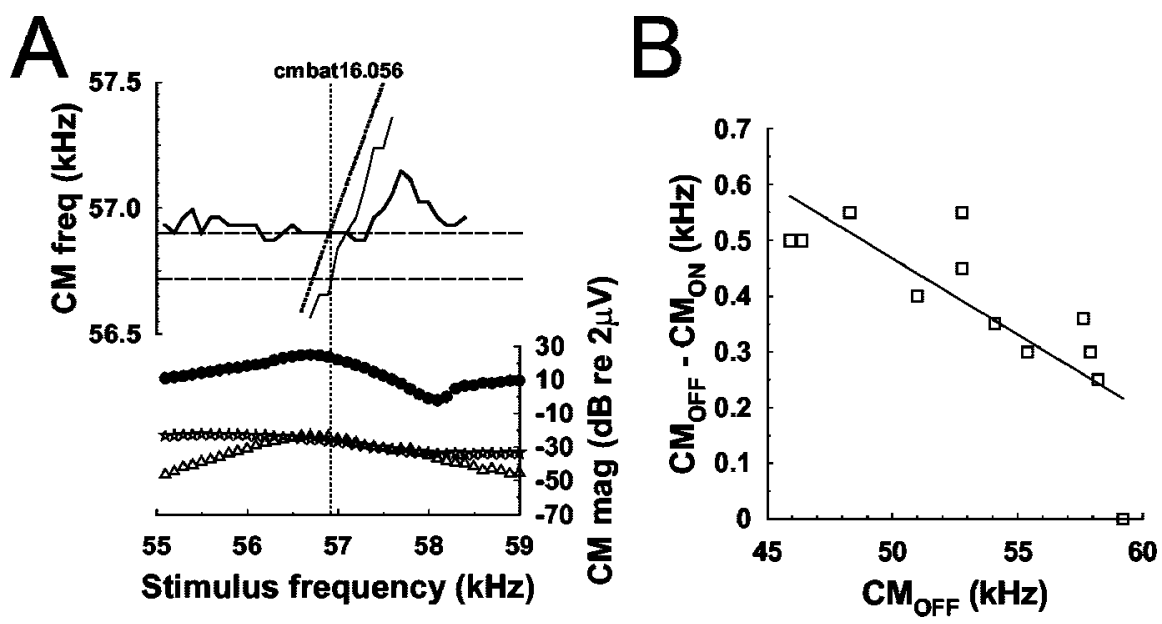

Figure 9. $A, C M$ frequency (top part) and CM magnitude (CM mag; bottom part) as functions of stimulus frequency measured in an immature bat (FAL, $40 \mathrm{~mm} ; 65 \mathrm{~dB}$ SPL). Symbols are as in Figure 8, showing the difference in frequency between the $\mathrm{CM}$ in the ringing after tone offset (thick trace, top dashed line) and at tone onset (thin trace, bottom dashed line). $B$, Difference in frequency between the $\mathrm{CM}$ in the ringing after tone offset and $\mathrm{CM}_{\mathrm{ON}}$ as a function of ringing frequency. The regression line has a slope of $-27.3 \pm 5.7 \mathrm{~Hz} / \mathrm{kHz}$. tuned onset oscillator. The offset oscillator phase leads the onset oscillator for frequencies below the resonance and lags it at frequencies above the resonance. As a consequence, there is an abrupt $360^{\circ}$ phase transition at the resonance frequency, which is also apparent in distortion product otoacoustic emission measured at the external auditory meatus (Russell and Kössl, 1999).

Development of the cochlear place

It is now well established, from measurements made in the cochleas of other CF bats (Rübsamen, 1987; Vater and Rübsamen, 1989), nonecholocating mammals (Harris and Dallos, 1984; Rübsamen and Lippe, 1998), and birds (Rubel and Ryals, 1983), that the characteristic frequency of a place on the BM shifts upward in frequency during development. If the natural frequency of the resonance $\omega$ is governed by the mass and stiffness of the cochlear partition, then $\omega=(k / m)^{1 / 2}$, where $k$ is stiffness, and $m$ is mass. The stiffness of the cochlear partition would have to almost double for an increase in resonance of $\sim 0.5$ octaves. There are no large-scale postnatal morphological changes in the cochlea of the mustached bat. However, differences in the physiological responses of immature and mature bat cochleas could be explained by differences in cellular skeletal and extracellular matrix morphology (Vater et al., 2003). An upward shift in frequency and enhanced resonance are associated with a stiffening and decreased damping of the cochlea. These changes would be facilitated by mechanical stiffening of cellular elements of the organ of Corti through the incorporation of cytoskeletal proteins, increased radial tension of the cochlear partition through the activity of the tensioning fibroblasts of the outer spiral ligament (Henson and Henson, 1988), and a reduction in the thickness of the tympanal layer of the BM (Vater et al., 2003).

Beating in the cochlea

Frequency beating to near-resonance ongoing tones is seen in $\mathrm{CM}$ responses from both mature and juvenile bats and is attributable to interaction between the sharply tuned cochlear resonance and the stimulus tone (Suga et al., 1975). The discovery of beating in the $\mathrm{CM}_{\mathrm{OFF}}$ recorded from the cochleas of bats that are close to maturity, but not in the resonance of sensitive mature bats, is a new finding. Similar beating has been observed in the CM ringing recorded from mature bats that have undergone gaseous anesthesia (Russell et 
al., 2003) and after activation of the cochlear efferents (Suga et al., 2000). The mechanical changes recorded in the cochleas of mature bats have been suggested to reflect mechanical uncoupling between two structural components of the cochlear partition attributable to dephosphorylation of $\mathrm{OHC}$ structural proteins (Russell et al., 2003). It may be that the offset beating recorded from immature bats is attributable to weak mechanical coupling between two structural components of the cochlea that becomes stronger during development.

\section{The development of the SI region as an "acoustic laser"}

Two frequency-matched oscillators that are actively pumped by the cochlear amplifier provide an acoustic laser that results in the very fine tuning of the SI region in the mustached bat's cochlea (Kössl and Russell, 1995, Russell and Kössl, 1999; Russell et al., 2003). The more broadly tuned onset oscillator, whose responses build up swiftly to resonance frequency tones, dominates the onset response. The narrowly tuned offset oscillator, which takes time to build up responses to resonance frequency tones, dominates the ringing. $\mathrm{CM}$ frequency measured at tone onset from the foveal region of the cochlea is not that of the tone but one of several frequency modes of the acoustic laser. The ringing has only a single mode. Thus, over a few milliseconds from tone onset, $\mathrm{OHC}$ mediated interaction between the two oscillators (presumably the BM and TM) results in acoustic lasing. The lasing modes change according to the stimulus frequency, the relative contributions of the two oscillators, and gain of $\mathrm{OHC}$ amplification to the acoustic laser.

In the first week of postnatal development, the mustached bat's cochlea behaves like an acoustic laser. The onset oscillator has many modes, which depend on stimulus frequency, but the offset oscillator is barely developed and is broadly tuned. The mode-hopping behavior at tone onset is very clear, with sharply defined frequency transitions between the frequency "plateaus." By the second week, the number of frequency modes at tone onset is slightly reduced. The ringing at tone offset is more prominent and is sustained at the resonance frequency over a $2-3 \mathrm{kHz}$ range of stimulus frequencies, which spans the $50-52 \mathrm{kHz}$ resonance frequency. The ringing also has several frequency modes that can be elicited by stimulus tones that differ from the resonance by $>1 \mathrm{kHz}$. These characteristics of the ringing, which are manifested in the second week, do not change qualitatively throughout the remaining period of postnatal development, although the resonance shifts to higher frequencies with advancing development. The increase in the ringing of $\mathrm{CM}_{\mathrm{OFF}}$ appears to be correlated with an increase in the rate of development of cochlear amplification in the second postnatal week (see Fig. 3D).
B

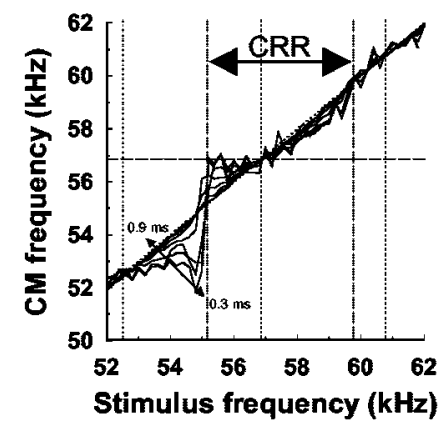

D

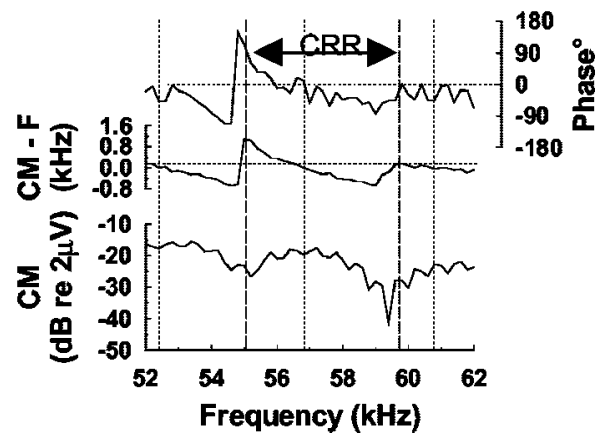

Figure 10. $\quad A, C M$ frequency (top part) and CM magnitude (bottom part) as functions of stimulus frequency measured in an immature bat (FAL, $47 \mathrm{~mm}$ ) in response to 10 msec tones at $80 \mathrm{~dB}$ SPL (open symbols) and $65 \mathrm{~dB} \mathrm{SPL}$ (filled symbols). Curves are (1) from 8196-point FFTs applied to $1 \mathrm{msec}$ sample periods measured $0 \mathrm{msec}$ (stars, thin line) and $6 \mathrm{msec}$ (circles) from the tone onset and $0.5 \mathrm{msec}$ from the tone offset (open triangles, thick line). $B$, Superimposed (M frequency as a function of stimulus from the tone onset. Diagonal dotted line, CM frequency = stimulus frequency; center vertical dotted line, resonance frequency $(56.9 \mathrm{kHz})$; vertical dashed lines, boundaries of the cochlear resonance region (CRR). C, Superimposed curves of CM - tone frequency as functions of stimulus frequency for $\mathrm{CM}$ measurements sampled for 1 msec periods taken with delays from the tone

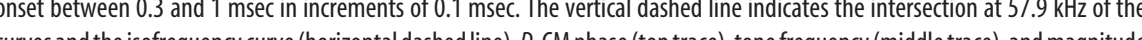
(bottom trace) as functions of stimulus frequency for measurements made $0.6 \mathrm{msec}$ from the onset of $10 \mathrm{msec}$ tone bursts from the same data as in A-C. Measurements were based on 8192-point FFTs applied to 1 msec sample periods of the CM data.

The behavior of the onset oscillator remains qualitatively the same throughout the entire period of postnatal development and resembles that of a synchronized oscillator (Strogatz, 1994; Russell et al., 2003). CM frequency in response to tones at and within $10 \mathrm{kHz}$ (at least) of the resonance is a compromise frequency that depends on the stimulus frequency, the frequency mode of the oscillator, and tone duration. $\mathrm{CM}_{\mathrm{ON}}$ attempts to "hunt" the stimulus frequency, and close to tone onset, the frequency of $\mathrm{CM}_{\mathrm{ON}}$ sharply undershoots and overshoots the stimulus frequency. These sudden frequency changes are associated with phase reversals and magnitude minima (Fig. 10D). A few milliseconds later, the system become more synchronized, and the $\mathrm{CM}_{\mathrm{ON}}$ frequency overshoots and undershoots become smoother (Fig. 10C). This is possibly attributable to the temporally related increase in $\mathrm{OHC}$ gain, which mediates the interaction between the onset and offset oscillators. In some bats (see Fig. $7 B, 8 B$ ), $\mathrm{CM}_{\mathrm{ON}}$ hunts not the stimulus frequency but a frequency proportional to it (indicated by the dashed lines). This might be because the frequencies of the onset and offset oscillators in these bats are far apart, and $\mathrm{CM}_{\mathrm{ON}}$ 
is a compromise frequency that is driven by both oscillators (Russell et al., 2003).

Thus, the foveal region of the mustached bat cochlea functions as an acoustic laser from birth. The foveal region of the cochlea is present, and the specialized basoapical gradients in morphology of the basilar and tectorial membranes that are essential components of the acoustic laser (Russell and Kössl, 1999) are established (Vater et al., 2003). Changes in the structure of the extracellular matrices and cytoskeletons of the cellular components of the cochlea, rather than in gross morphology, appear to be responsible for the maturation and sharp tuning of this highly resonant biological structure.

\section{References}

Brownell WE, Bader CR, Bertrand D, Ribaupierre YD (1985) Evoked mechanical responses of isolated outer hair cells. Science 227:194-196.

Dallos P (1992) The active cochlea. J Neurosci 12:4575-4585.

Dallos P, Billone MC, Durrant JD, Wang C, Raynor S (1972) Cochlear inner and outer hair cells: functional differences. Science 177:356-358.

Davis H (1965) A model for transduction action in the cochlea. Cold Spring Harbor Symp Quant Biol 30:181-190.

Engström H, Engström B (1978) Structure of the hairs on cochlear sensory cells. Hear Res 1:49-66.

Geisler CD, Sang C (1995) A cochlear model using feed-forward outer hair cell forces. Hear Res 86:132-146.

Gummer AW, Hemmert W, Zenner HP (1996) Resonant tectorial membrane motion in the inner ear: its crucial role in frequency tuning. Proc Natl Acad Sci USA 93:8727-8732.

Harris DM, Dallos P (1984) Ontogenetic changes in frequency mapping of a mammalian ear. Science 225:741-743.

Henson MM, Henson Jr OW (1988) Tension fibroblasts and the connective tissue matrix of the spiral ligament. Hear Res 35:237-258.

Henson MM, Henson Jr OW (1991) Specializations for sharp tuning in the mustached bat: the tectorial membrane and the spiral limbus. Hear Res $56: 122-132$

Henson Jr OW, Pollak GD (1972) A technique for chronic implantation of electrodes in the cochleae of bats. Physiol Behav 8:1185-1188.

Henson Jr OW, Schuller G, Vater MA (1985) Comparative study on the physiological properties of the inner ear in Doppler shift compensating bats. J Comp Physiol [A] 157:587-597.

Henson Jr OW, Xie DH, Keating AW, Henson MM (1995) The effect of contralateral stimulation on the cochlear resonance and damping in the mustached bat: the role of the medial efferent system. Hear Res 86:111-124.

Kimura RS (1966) Hairs of the cochlear sensory cells and their attachment to the tectorial membrane. Acta Otolaryngol 61:55-72.

Kössl M, Russell IJ (1995) Basilar membrane resonance in the mustached bat. Proc Natl Acad Sci USA 92:276-279.

Kössl M, Vater M (1985) The cochlear frequency map of the mustached bat, Pteronotus parnellii. J Comp Physiol [A] 157:687-697.

Kössl M, Mayer F, Frank G, Faulstich M, Russell IJ (1999) Evolutionary adaptations of cochlear function in Jamaican mormoopid bats. J Comp Physiol [A] 185:217-229.

Kössl M, Foeller E, Drexl M, Mora E, Coro F, Russell IJ (2003) Postnatal development of cochlear function in the mustached bat, Pteronotus parnellii. J Neurophysiol 90:2261-2273.

Kunz TH, Anthony ELP (1982) Age estimation and post-natal growth in the bat Myotis lucifugus. J Mammal 63:23-32.

Legan KP, Lukashkina VA, Goodyear RJ, Kössl M, Russell IJ, Richardson GP (2000) A targeted deletion in $\alpha$-tectorin reveals that the tectorial mem- brane is required for the gain and timing of cochlear feedback. Neuron 28:273-285.

Lukashkin AN, Russell IJ (2003) A second, low frequency mode of vibration in the intact mammalian cochlea. J Acoust Soc Am 113:1544-1550.

Markin VS, Hudspeth AJ (1995) Modelling the active process of the cochlea: phase relations, amplification, and spontaneous oscillation. Biophys J 69:138-147.

Neuweiler G (1990) Auditory adaptations for prey capture in echolocating bats. Physiol Rev 70:615-641.

Nilsen KE, Russell IJ (1999) Timing of cochlear feedback: spatial and temporal representation of a tone across the basilar membrane. Nat Neurosci 2:642-648.

Patuzzi R, Yates GK, Johnstone BM (1989) The origin of low frequency microphonic in the first turn of guinea pig. Hear Res 39:177-188.

Robles L, Ruggero MA (2001) Mechanics of the mammalian cochlea. Physiol Rev 81:1305-1352.

Rubel EW, Ryals BM (1983) Development of the place principle: acoustic trauma. Science 219:512-514.

Rübsamen R (1987) Ontogenesis of the echolocation system in the rufous horseshoe bat, Rhinolophus rouxi (audition and vocalization in early postnatal development). J Comp Physiol [A] 161:899-904.

Rübsamen R, Lippe WR (1998) The development of cochlea function. In: Springer handbook of auditory research: development of the auditory system (Fay R, Popper AN, eds), pp 193-270. New York: Springer.

Russell IJ, Kössl M (1992) Sensory transduction and frequency selectivity in the basal turn of the guinea-pig cochlea. Philos Trans R Soc Lond B Biol Sci 336:317-324.

Russell IJ, Kössl M (1999) Micromechanical responses to tones in the auditory fovea of the greater mustached bat's cochlea. J Neurophysiol $82: 676-686$

Russell IJ, Sellick PM (1983) Low frequency characteristics of intracellular receptor potentials recorded in mammalian hair cells. J Physiol (Lond) 33:179-206.

Russell IJ, Cody AR, Richardson GP (1986) The responses of inner and outer hair cells in the basal turn of the guinea-pig cochlea and in the mouse cochlea grown in vitro. Hear Res 22:199-216.

Russell IJ, Drexl M, Foeller E, Vater M, Kössl M (2003) Synchronization of a non-linear oscillator: processing the CF component of the echo response signal in the cochlea of the mustached bat. J Neurosci, in press.

Schnitzler H-U, Kalkow E (1998) How echolocating bats search and find food. In: Bats, phylogeny, morphology, echolocation, and conservation biology (Kunz TH, Racey PA, eds), pp 183-197. Washington, DC: Smithsonian Institution.

Silva Taboada G (1979) Los murcielagos de Cuba. Havana: Editorial Academia, La Habana Cuba.

Strogatz SH (1994) Nonlinear dynamics and chaos: with applications to physics, biology, chemistry, and engineering. Reading, MA: Addison-Wesley.

Suga N, Simmons JA, Shimozawa T (1974) Neurophysiological studies on echolocation systems in bats producing CF.FM orientation sounds. J Exp Biol 61:379.

Suga N, Simmons JA, Jen HPS (1975) Peripheral specialization for fine analysis of Doppler shifted echoes in the auditory system of the CF-FM bat Pteronotus parnellii. J Exp Biol 63:61-192.

Suga N, Gao E, Zhang Y, Ma X, Olsen J (2000) The corticofugal system for hearing: recent progress. Proc Natl Acad Sci USA 97:11807-11814.

Vater M, Rübsamen R (1989) Postnatal development of the cochlea in horseshoe bats. In: Cochlear mechanisms (Wilson JP, Kemp DT, eds), pp 217-225. New York: Plenum.

Vater M, Kössl M, Foeller E, Coro F, Mora E, Russell IJ (2003) Development of sonar signals in the mustached bat, Pteronotus parnellii. J Neurophysiol 90:2274-2290. 